\title{
ANALISIS TRANSFORMASI DATUM \\ DARI DATUM INDONESIA 1974 KE DATUM GEODESI NASIONAL 1995
}

\author{
Eko Yuli Handoko * dan Hasanuddin Z. Abidin ** \\ * Program Studi Teknik Geodesi, FTSP, Institut Teknologi Sepuluh Nopember - Surabaya \\ ** Departemen Teknik Geodesi, FTSP, Institut Teknologi Bandung
}

\begin{abstract}
ABSTRAK
Program pemetaan nasional diharapkan menggunakan datum geodetik nasional yaitu Datum Geodesi Nasional (DGN95). Namun masih banyak peta atau data geodesi yang mempunyai datum yang berbeda dengan DGN95, misalnya datum Indonesia Datum 1974 (ID74). Untuk itu perlu suatu model transformasi datum antara datum ID74 ke datum DGN95. Tulisan ini membahas hal tersebut dengan mempertimbangkan dua model transformasi yaitu : Model Transformasi 7 Parameter / Similarity Transformation ( BursaWolf) dan Model Transformasi 10 Parameter / Affinity Transformation. Dengan menggunakan data titik sekutu yang ada, dihitung parameter transformasi dari dua model tersebut di atas. Dari hasil kedua model tersebut dianalisis sehingga dapat diketahui model yang mana yang memberikan hasil optimum.
\end{abstract}

Kata kunci : datum, transformasi, ID74, DGN95

\section{PENDAHULUAN}

Dengan keppres No. 166 Tahun 2000 Bakosurtanal kembali diberi tugas untuk menyelenggarakan tugas pemerintahan di bidang survei dan pemetaan sesuai dengan peraturan perundang-undangan yang berlaku. Dalam menyelenggarakan tugas itu untuk pertama kalinya secara eksplisit ditetapkan bahwa Bakosurtanal mempunyai fungsi pembinaan infrastruktur data spasial atau yang lebih dikenal sebagai Infrastruktur Data Spasial Nasional (IDSN).

Infrastruktur Data Spasial Nasional (IDSN) dilihat sebagai satu upaya nasional untuk menghadirkan sumber-sumber data spasial dasar yang dapar dimanfaatkan seluas mungkin. IDSN harus menyediakan tema-tema data spasial yang paling umum digunakan oleh pengguna, dan terkait dengan penciptaan satu lingkungan yang mendukung pengembangan dan pemanfaatan data spasial secara optimal.

Selanjutnya semua program pemetaan nasional maupun daerah diharapkan menggunakan georeferensi standar nasional yaitu Datum Geodesi Nasional 1995 (DGN95). Pemetaan ke dalam sistem DGN95 dapat dilakukan dengan pengikatan ke kerangka kontrol horisontal Bakosurtanal Orde 0 dan Orde 1, serta ke Titik Dasar Teknik BPN, Orde II, III, dan IV. Ini adalah satu framework dataset atau data dasar utama dalam kerangka IDSN ( Villanueva, 2001 ).

Dalam perjalanannya, Indonesia pernah mempunyai beberapa datum sebagai sistem referensi pemetaan. Berbagai datum tersebut antara lain Datum Genuk ( Pulau Jawa ) menggunakan model ellisoid Bessel 1841 yang ditentukan menggunakan metode triangulasi, Indonesia Datum 1974 menggunakan ellipsoid referensi SNI (Sferoid Nasional Indonesia) dengan pengamatan menggunakan metode Doppler. Sekarang, dengan kemajuan teknologi Satelit Global Positioning System (GPS) , Indonesia menetapkan datum yaitu Datum Geodesi Nasional 1995 (DGN-95) yang geosentrik. Datum ini ditentukan menggunakan pengamatan GPS dan menggunakan ellipsoid referensi WGS-84.

Mengingat peta-peta yang ada sekarang ini masih banyak yang menggunakan sistem lama (ID-74), sesuai dengan diselenggarakannya IDSN yang mempunyai standard, salah 
satunya bahwa datum yang digunakan adalah datum DGN-95 (Matindas, 2002 ), maka perlu dilakukan transformasi datum menjadi datum DGN-95.

Dalam transformasi datum dari datum ID-74 ke Datum DGN-95 menggunakan model transformasi datum. Terdapat bermacam-macam model dalam transformasi datum. Model transformasi datum tersebut yang akan dibahas dalam makalah ini antara lain :

- Similarity transformation model ( model Bursa-Wolf)

- Affinity transformation model ( 10 parameter transformasi)

Hitungan dilakukan dengan menggunakan data seluruh titik sekutu ( 35 titik sekutu ) dan hitungan menggunakan data yang dibagi menjadi dua wilayah yaitu wilayah 1 dan wilayah 2 ( terlihat dalam gambar 1 )

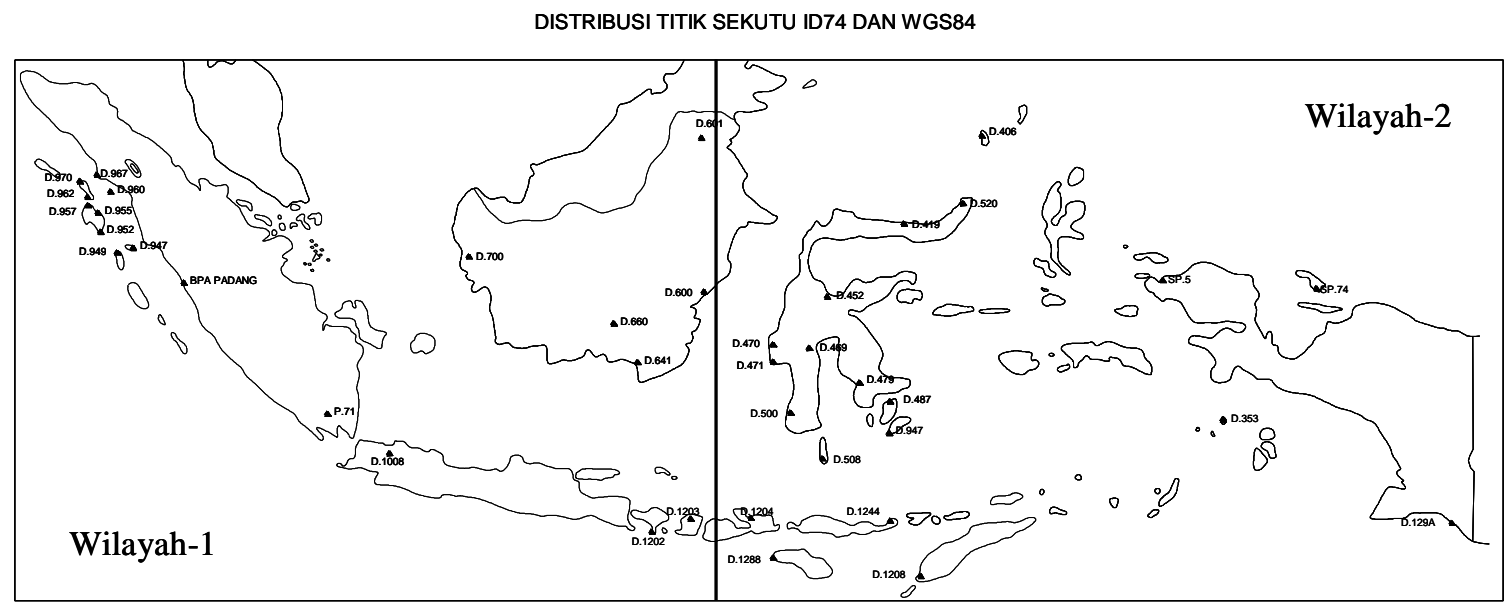

Gambar 1. Distribusi Titik Sekutu dalam Sistem ID74 dan DGN94

\section{MODEL TRANSFORMASI DATUM}

\subsection{Transformasi 7 Parameter (Bursa-Wolf)}

Kita mengenal beberapa model transformasi koordinat, salah satunya transformasi dengan 7 parameter, yaitu : 3 rotasi, 3 translasi, dan faktor skala. Model ini sering disebut juga sebagai model linear conformal in three dimension atau three dimensional similarity transformation. Hal ini disebabkan bahwa dalam model ini faktor skala pada semua arah adalah sama. Dalam model ini bentuk jaringan dipertahankan, maka sudut tidak berubah, tetapi panjang baseline dan posisi titik dapat berubah. Menggunakan model three dimensional similarity transformation pada jaring kerangka yang besar mungkin dapat mengubah skala lokal dan orientasi. Oleh karena itu, perlu dipertimbangkan apakah perubahan pada skala lokal dan orientasi ini memberikan pengaruh secara signifikan atau tidak.

Jika $\mathbf{X}_{\mathbf{A}}=\left[\mathbf{x}_{\mathbf{A}}, \mathbf{y}_{\mathbf{A}}, \mathbf{z}_{\mathbf{A}}\right]^{\mathbf{t}}$ dan $\mathbf{X}_{\mathbf{B}}=\left[\mathbf{x}_{\mathbf{B}}, \mathbf{y}_{\mathbf{B}}, \mathbf{z}_{\mathbf{B}}\right]^{\mathbf{t}}$ adalah koordinat sebelum dan sesudah ditransformasi, maka model fungsional dari transformasi dengan 7 parameter adalah sebagai berikut :

$$
\mathbf{X}_{B}=\text { s. } R . \mathbf{X}_{A}+\mathbf{t}
$$

dengan ;

$$
\begin{array}{ll}
\mathbf{s} & =\text { faktor skala } \\
\mathbf{t} & =\text { vektor translasi }\left(\mathrm{t}_{\mathrm{x}}, \mathrm{t}_{\mathrm{y}}, \mathrm{t}_{\mathrm{z}}\right)^{\mathrm{t}} \\
\mathbf{R} & =\text { matrik ortogonal dari rotasi sistem } \mathbf{x}_{\mathbf{1}} \text { ke sistem } \mathbf{x}_{\mathbf{2}} \text {, yaitu : }
\end{array}
$$




$$
R=\left(\begin{array}{ccc}
\cos \kappa \cdot \cos \theta & \cos \kappa \cdot \sin \theta \cdot \sin \omega+\sin \kappa \cdot \cos \omega & \sin \kappa \cdot \sin \omega-\cos \kappa \cdot \sin \theta \cdot \cos \omega \\
-\sin \kappa \cdot \cos \theta & \cos \kappa \cdot \cos \omega-\sin \kappa \cdot \sin \theta \cdot \sin \omega & \sin \kappa \cdot \sin \theta \cdot \cos \omega+\cos \kappa \cdot \sin \omega \\
\sin \theta & -\cos \theta \cdot \sin \omega & \cos \theta \cdot \cos \omega
\end{array}\right)
$$

Secara numerik hasil transformasi menggunakan model Bursa-Wolf dapat ditunjukan dalam Tabel 1,2 dan 3

Tabel 1. Parameter transformasi Bursa-Wolf dari ID74 ke DGN95

\begin{tabular}{|c|c|c|}
\hline parameter & nilai & satuan \\
\hline$\Delta \mathrm{X}$ & -20.167 & meter \\
\hline$\Delta \mathrm{Y}$ & -38.719 & meter \\
\hline$\Delta Z$ & 47.284 & meter \\
\hline $\mathrm{rx}$ & 1.323 & detik \\
\hline $\mathrm{ry}$ & 0.520 & detik \\
\hline $\mathrm{rz}$ & 0.634 & detik \\
\hline $\mathrm{ds}$ & $1.467 \times 10^{-6}$ & - \\
\hline
\end{tabular}

Tabel 2. Parameter transformasi Bursa-Wolf dari ID74 ke DGN95 Wilayah 1

\begin{tabular}{|c|c|c|}
\hline parameter & nilai & satuan \\
\hline$\Delta \mathrm{X}$ & -19.743 & meter \\
\hline$\Delta \mathrm{Y}$ & -9.860 & meter \\
\hline$\Delta \mathrm{Z}$ & -13.589 & meter \\
\hline $\mathrm{rx}$ & -0.555 & detik \\
\hline $\mathrm{ry}$ & -0.117 & detik \\
\hline $\mathrm{rZ}$ & -0.883 & detik \\
\hline $\mathrm{ds}$ & $-1.313 \times 10^{-06}$ & - \\
\hline
\end{tabular}

Tabel 3. Parameter transformasi Bursa-Wolf dari ID74 ke DGN95 Wilayah 2

\begin{tabular}{|c|c|c|}
\hline parameter & nilai & satuan \\
\hline$\Delta \mathrm{X}$ & -40.976 & meter \\
\hline$\Delta \mathrm{Y}$ & -185.309 & meter \\
\hline$\Delta Z$ & 9.876 & meter \\
\hline $\mathrm{rx}$ & -0.428 & detik \\
\hline $\mathrm{ry}$ & 0.760 & detik \\
\hline $\mathrm{rz}$ & 6.825 & detik \\
\hline $\mathrm{ds}$ & $8.321 \times 10^{-06}$ & - \\
\hline
\end{tabular}

\subsection{Transformasi 10 Parameter (Affinity Model)}

Secara praktis, jika kita ingin mentransformasikan satu sistem koordinat ke sistem koordinat yang lain, digunakan transformasi menggunan 7 parameter, 3 parameter rotasi, 3 parameter translasi, dan faktor skala. Implikasi dari model ini adalah posisi titik dan panjang baseline akan berubah, tetapi sudut dan bentuk jaringan tidak berubah. Sering kali model ini tidak cukup merefreksikan situasi yang sebenarnya (Wolfrum, 1992 ). Dari teori permukaan (Hotine, 1947; Wolfrum,1992) bahwa setiap perubahan, bagian kecil dipermukaan, cenderung diasumsikan sebagai karakter dari affinity.

Jika sistem koordinat $\mathrm{A}$ yang dinyatakan dalam $\mathrm{S}_{\mathrm{u}}$ ditransformasikan kedalam sistek koordinat $\mathrm{B}$ yang dinyatakan dalam $\mathrm{S}_{\mathrm{x}}$, dengan affinity transformation model, dilakukan langkah-langkah sebagai berikut. Langkah pertama adalah mentransformasikan vektor posisi $u$ ke dalam sistek koordinat lokal $\mathrm{S}_{\mathrm{L}}$ dengan $\mathrm{P}_{0}$ adalah centroid dari jaringan. $\mathrm{w}_{\mathrm{L}}$ adalah normal ellipsoid. $\mathrm{u}_{\mathrm{L}}$ adalah pararel meredian, sedangkan $\mathrm{v}_{\mathrm{L}}$ adalah siku dari $\mathrm{u}_{\mathrm{L}}$ ke arah timur. Vektor posisi $u$ dalam sistem $\mathrm{S}_{\mathrm{L}}$ : 


$$
\mathrm{u}_{\mathrm{L}}=\mathrm{M}\left(\mathrm{u}-\mathrm{u}_{0}\right)=\mathrm{M} \cdot \Delta \mathrm{u}
$$

dimana :

$$
\begin{gathered}
\mathrm{M}=\mathrm{P}_{2} \mathrm{R}_{2}\left(\varphi_{0}-\frac{\pi}{2}\right) \mathrm{R}_{3}\left(\lambda_{0}-\pi\right) \\
\mathrm{M}=\left[\begin{array}{ccc}
-\sin \varphi_{0} \cos \lambda_{0} & -\sin \varphi_{0} \sin \lambda_{0} & \cos \varphi_{0} \\
-\sin \lambda_{0} & \cos \lambda_{0} & 0 \\
\cos \varphi_{0} \sin \lambda_{0} & \cos \varphi_{0} \sin \lambda_{0} & \sin \varphi_{0}
\end{array}\right] \quad P_{2}=\left[\begin{array}{ccc}
1 & 0 & 0 \\
0 & -1 & 0 \\
0 & 0 & 1
\end{array}\right]
\end{gathered}
$$

Langkah kedua adalah memmasukkan unsur affinitas. Sistem lokal $\mathrm{S}_{\mathrm{L}}$ diputar / dirotasi pada sumbu $\mathrm{w}_{\mathrm{L}}$ sebesar sudut $\alpha$ searah jarum jam, sehingga terdapat distorsi skala yaitu $\left(\mathrm{k}_{1}, \mathrm{k}_{2}, \mathrm{k}_{3}\right)$ Selanjutnya diputar kempali sebesar sudut $(-\alpha)$, berlawaan arah jarum jam, sehingga diperoleh :

dengan :

$$
\mathrm{u}_{\mathrm{L}}^{\prime}=\mathrm{R}_{3}(-\alpha) \mathrm{KR}_{3}(\alpha) \mathrm{u}_{\mathrm{L}}=\mathrm{S} \cdot \mathrm{u}_{\mathrm{L}}
$$

$$
\begin{aligned}
\mathrm{K} & =\left[\begin{array}{ccc}
\mathrm{k}_{1} & 0 & 0 \\
0 & \mathrm{k}_{2} & 0 \\
0 & 0 & \mathrm{k}_{3}
\end{array}\right] \\
\mathrm{S} & =\left[\begin{array}{ccc}
\mathrm{k}_{1} \cos ^{2} \alpha+\mathrm{k}_{2} \sin ^{2} \alpha & \left(\mathrm{k}_{1}-\mathrm{k}_{2}\right) \sin \alpha \cdot \cos \alpha & 0 \\
\left(\mathrm{k}_{1}-\mathrm{k}_{2}\right) \sin \alpha \cdot \cos \alpha & \mathrm{k}_{1} \sin ^{2} \alpha+\mathrm{k}_{2} \cos ^{2} \alpha & 0 \\
0 & 0 & \mathrm{k} 3
\end{array}\right]
\end{aligned}
$$

dimana $S$ adalah matrik empat parameter affinity.

Hal di atas dapat berarti $\alpha, \mathrm{k}_{1}, \mathrm{k}_{2}$ merupakan model sistematik distorsi affine dalam arah horisontal $\mathrm{u}_{\mathrm{L}}$ dan $\mathrm{v}_{\mathrm{L}}$. Sedangkan $\mathrm{k}_{3}$ merupakan besarnya perbedaan skala tinggi . Selanjutnya, perbedaan orientasi antara dua sistem diperhitungkan. Seperti dalam Veis (1962), model deferensial parameter orientasi $d A, d \mu, d v$ merujuk pada sistem lokal $\mathrm{S}_{\mathrm{L}}$.

Akhirnya peralihan sistem $\mathrm{S}_{\mathrm{X}}$ didapatkan dengan membalikan rumus transformasi $\mathrm{u}_{\mathrm{L}}=$ $\mathrm{M}\left(\mathrm{u}-\mathrm{u}_{0}\right)=\mathrm{M} . \Delta \mathrm{u}$. Matrik $\mathrm{M}$ merupakan matrik orthogonal sehingga $\mathrm{M}^{-1}=\mathrm{M}^{\mathrm{T}}$, maka :

$$
\Delta \mathrm{x}=\mathrm{M}^{\mathrm{T}} \cdot \mathrm{R} \cdot \Delta \cdot \mathrm{u}_{\mathrm{L}}{ }^{\prime}
$$

dimana :

$$
R=\left[\begin{array}{ccc}
1 & d A & -d \mu \\
-d A & 1 & d v \\
d \mu & -d \nu & 1
\end{array}\right]
$$

dengan mensubsitusi persamaan sebelumnya maka bentuk dari persamaan perbedaan vektor $\Delta \mathrm{x}$ dan $\Delta . \mathrm{u}$ adalah :

$$
\Delta \mathrm{x}=\mathrm{M}^{\mathrm{T}} \text {. R. S . M. } \Delta . \mathrm{u}
$$

atau untuk vektor $\mathrm{u}$, persamaan transformsai sebagai berikut berlaku:

$$
x=t+u_{0}+M^{T} \cdot R \cdot S \cdot M \cdot\left(u-u_{0}\right)
$$

dimana $t$ adalah vektor translasi antara dua sistem. 
Prosedur hitungan perataannya memerlukan model yang linier dari fungsi yang tidak diketahui. Oleh karena itu. Disederhanakan matrik affinity menjadi, sebagai berikut :

$$
S=\left[\begin{array}{lll}
p & q & 0 \\
q & r & 0 \\
0 & 0 & s
\end{array}\right]
$$

dimana :

$$
\begin{aligned}
& \mathrm{p}=\mathrm{k}_{1} \cos ^{2} \alpha+\mathrm{k}_{2} \sin ^{2} \alpha \\
& \mathrm{r}=\mathrm{k}_{1} \sin ^{2} \alpha+\mathrm{k}_{2} \cos ^{2} \alpha \\
& \mathrm{s}=\mathrm{k}_{3} \\
& \mathrm{q}=\left(\mathrm{k}_{1}-\mathrm{k}_{2}\right) \sin \alpha \cdot \cos \alpha
\end{aligned}
$$

Jika persamaan diatas didekati dengan suatu mdel pendekatan, maka persamaan tersebut dapat ditulis kembali :

$$
\begin{array}{ll}
\mathrm{p}=\mathrm{p}_{0}+\mathrm{dp} & \mathrm{p}_{0}=1 \\
\mathrm{r}=\mathrm{r}_{0}+\mathrm{dr} & \mathrm{r}_{0}=1 \\
\mathrm{~s}=\mathrm{s}_{0}+\mathrm{ds} & \mathrm{s}_{0}=1 \\
\mathrm{q}=\mathrm{q}_{0}+\mathrm{dq} & \mathrm{q}_{0}=1
\end{array}
$$

sehingga matrik affinity dapat dibentuk menjadi persamaan :

$$
S=I+d S
$$

Dengan

$$
\mathrm{dS}=\left[\begin{array}{ccc}
\mathrm{dp} & \mathrm{dq} & 0 \\
\mathrm{dq} & \mathrm{dr} & 0 \\
0 & 0 & \mathrm{ds}
\end{array}\right]
$$

seperti hal di atas, maka untuk R menjadi ;

$$
\mathrm{R}=\mathrm{I}+\mathrm{dR}
$$

Maka dengan mengabaikan bentuk orde dua, perkalian product R.S dapat ditulis menjadi :

$$
\text { R.S }=I+d R+d S
$$

Sehingga persamaan linier dari model transformasi menjadi :

$$
x=u+t+M^{T}(d R+d S) M \cdot \Delta u
$$

atau

$$
\mathrm{x}=\mathrm{u}+\mathrm{t}+\mathrm{G}\left(\mathrm{u}-\mathrm{u}_{0}\right)
$$

Pada persamaan di atas matriks G mempunyai struktur sebagai berikut : 


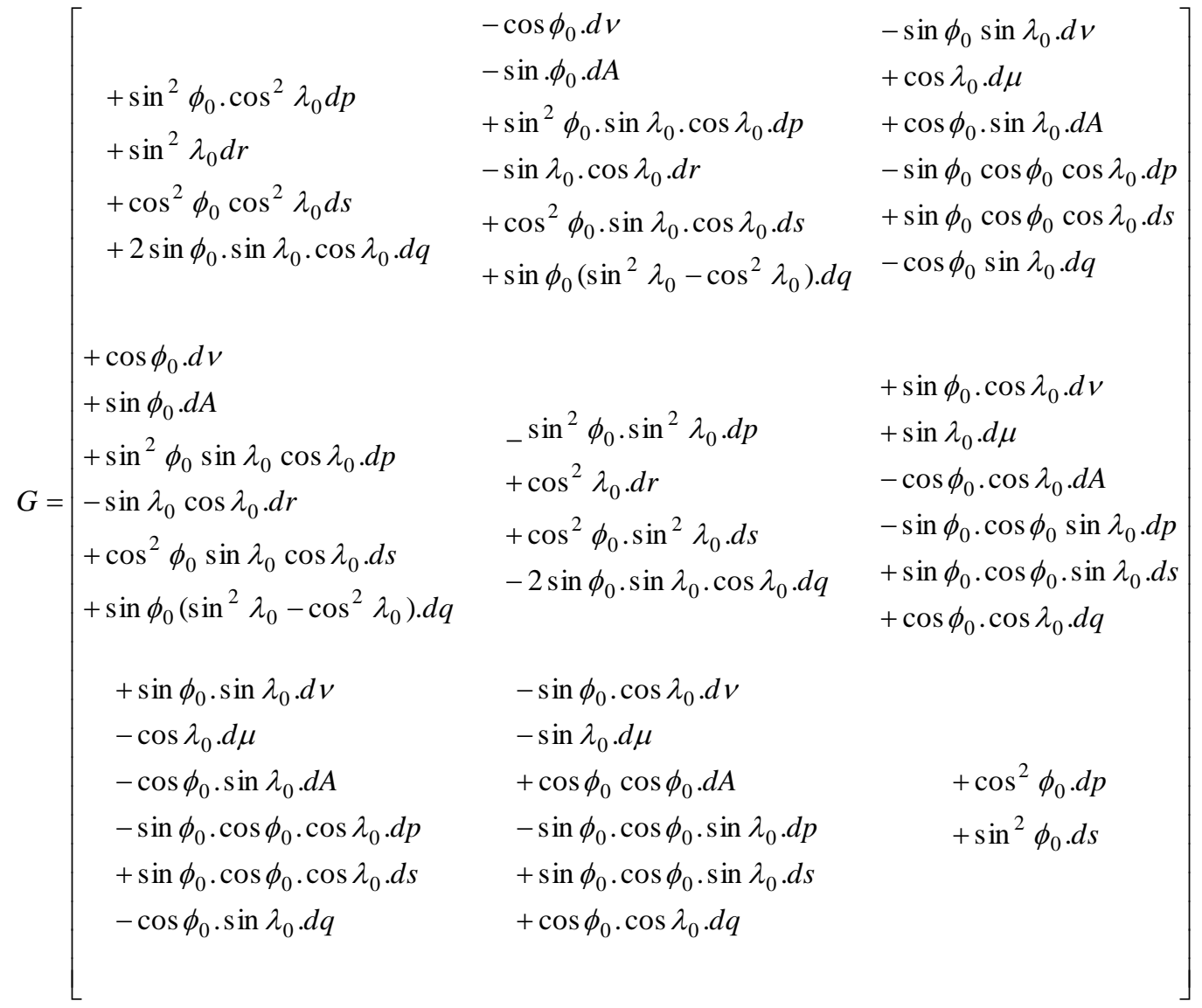

Untuk menghitung nilai parameter, digunakan metode standard seperti dalam Mikhail (1976);

$$
\mathrm{F}_{\mathrm{i}} \equiv\left(\mathrm{u}_{\mathrm{i}}+\mathrm{v}_{\mathrm{u}_{\mathrm{i}}}\right)+\mathrm{G} \cdot \Delta \mathrm{u}_{\mathrm{i}}-\left(\mathrm{x}_{\mathrm{i}}+\mathrm{v}_{\mathrm{x}_{\mathrm{i}}}\right)=0
$$

yang kemudian dalam bentuk linier :

$$
\mathrm{A}_{\mathrm{i}} \mathrm{v}_{\mathrm{i}}+\mathrm{B}_{\mathrm{i}} \Delta=\mathrm{w}_{\mathrm{i}}=0
$$

dengan :

$$
\begin{aligned}
& \mathrm{v}_{\mathrm{i}}^{\mathrm{T}}=\left[\begin{array}{ll}
\mathrm{v}_{\mathrm{u}_{\mathrm{i}}^{\mathrm{T}}}^{\mathrm{T}} & \mathrm{v}_{\mathrm{x}_{\mathrm{i}}}^{\mathrm{T}}
\end{array}\right]=\left[\mathrm{v}_{\mathrm{u}}, \mathrm{v}_{\mathrm{v}}, \mathrm{v}_{\mathrm{w}}, \mathrm{v}_{\mathrm{x}}, \mathrm{v}_{\mathrm{y}}, \mathrm{v}_{\mathrm{y}}\right]_{\mathrm{i}} \\
& \Delta^{\mathrm{T}}=\left[\mathrm{t}_{\mathrm{x}}, \mathrm{t}_{\mathrm{y}}, \mathrm{t}_{\mathrm{z}}, \mathrm{d}_{\mathrm{v}}, \mathrm{d}_{\mu}, \mathrm{dA}, \mathrm{dp}, \mathrm{dr}, \mathrm{ds}, \mathrm{dq}\right] \\
& \mathrm{w}_{\mathrm{i}}=\mathrm{u}_{\mathrm{i}}-\mathrm{x}_{\mathrm{i}} \\
& \mathrm{A}_{\mathrm{i}}=\frac{\delta \mathrm{F}_{\mathrm{i}}}{\delta\left(\mathrm{L}_{\mathrm{i}}+\mathrm{v}_{\mathrm{i}}\right)} \quad \mathrm{B}_{\mathrm{i}}=\frac{\delta \mathrm{F}_{\mathrm{i}}}{\delta \Delta}
\end{aligned}
$$

dimana :

$$
\mathrm{L}_{\mathrm{i}}^{\mathrm{T}}=\left\lfloor\mathrm{u}_{\mathrm{i}}^{\mathrm{T}}, \mathrm{x}_{\mathrm{i}}^{\mathrm{T}}\right\rfloor=[\mathrm{u}, \mathrm{v}, \mathrm{w}, \mathrm{x}, \mathrm{y}, \mathrm{z}]_{\mathrm{i}}
$$

Secara numerik hasil transformasi menggunakan model 10 parameter dapat ditunjukan dalam Tabel 4,5 dan 6 . 
Tabel 4. Parameter transformasi affin 10 parameter dari ID74 ke DGN95

\begin{tabular}{|c|c|c|}
\hline parameter & nilai & satuan \\
\hline$\Delta \mathrm{X}$ & -21.113 & meter \\
\hline$\Delta \mathrm{Y}$ & -24.247 & meter \\
\hline$\Delta Z$ & 4.033 & meter \\
\hline $\mathrm{d} \mu$ & 0.3618 & detik \\
\hline $\mathrm{d} v$ & -0.613 & detik \\
\hline $\mathrm{dA}$ & -0.346 & detik \\
\hline $\mathrm{dp}$ & -0.0000018792988 & - \\
\hline $\mathrm{dr}$ & 0.00000175379386 & - \\
\hline $\mathrm{ds}$ & -0.0000703977996 & - \\
\hline $\mathrm{dq}$ & 0.00000149589559 & - \\
\hline
\end{tabular}

Tabel 5. Parameter transformasi affin 10 parameter dari ID74 ke DGN95 Wilayah 1

\begin{tabular}{|c|c|c|}
\hline parameter & nilai & satuan \\
\hline$\Delta \mathrm{X}$ & -20.192 & meter \\
\hline$\Delta \mathrm{Y}$ & -24.339 & meter \\
\hline$\Delta Z$ & 3.852 & meter \\
\hline $\mathrm{d} \mu$ & -0.450 & detik \\
\hline $\mathrm{d} v$ & 0.708 & detik \\
\hline $\mathrm{dA}$ & -0.140 & detik \\
\hline $\mathrm{dp}$ & -0.00000125099 & - \\
\hline $\mathrm{dr}$ & -0.00000008157 & - \\
\hline $\mathrm{ds}$ & 0.00000874641 & - \\
\hline $\mathrm{dq}$ & 0.00000049548 & - \\
\hline
\end{tabular}

Tabel 6. Parameter transformasi affin 10 parameter dari ID74 ke DGN95 Wilayah 2

\begin{tabular}{|c|c|c|}
\hline parameter & nilai & satuan \\
\hline$\Delta \mathrm{X}$ & -22.088 & meter \\
\hline$\Delta \mathrm{Y}$ & -24.150 & meter \\
\hline$\Delta Z$ & 4.226 & meter \\
\hline $\mathrm{d} \mu$ & 0.678 & detik \\
\hline $\mathrm{d} v$ & -2.666 & detik \\
\hline $\mathrm{dA}$ & 0.011 & detik \\
\hline $\mathrm{dp}$ & -0.0000018140325 & - \\
\hline $\mathrm{dr}$ & 0.0000035919645 & - \\
\hline $\mathrm{ds}$ & -0.0002048647734 & - \\
\hline $\mathrm{dq}$ & 0.0000002310080 & - \\
\hline
\end{tabular}

\section{ANALISIS HASIL HITUNGAN}

Dengan semua hasil yang ada, yang telah dihitung menggunakan model-model transformasi yang tersebut diatas, hasil tersebut dibandingkan dengan nilai koordinat titik sekutu dalam sistem DGN95. Hasil berupa grafik selisih dapat ditunjukkan dalam Gambar 2, 3, 4, 5, 6, \& 7 .

Transformasi menggunakan model 7 parameter dengan semua data titik sekutu ( 35 titik ) seperti ditunjukkan dalam gambar 2 mempunyai variasi penyimpangan yang relatif sama, kecuali terdapat beberapa titik yang berbeda. Dari hasil tersebut dapat diketahui penyimpangan rata-rata $\Delta \mathrm{X} \approx 34.614 \mathrm{~m}, \Delta \mathrm{Y} \approx 26.133 \mathrm{~m}$ dan $\Delta \mathrm{Z} \approx 4.033 \mathrm{~m}$; 
Selisih Koordinat Hasil Transformasi \& Titik Sekutu - DGN95

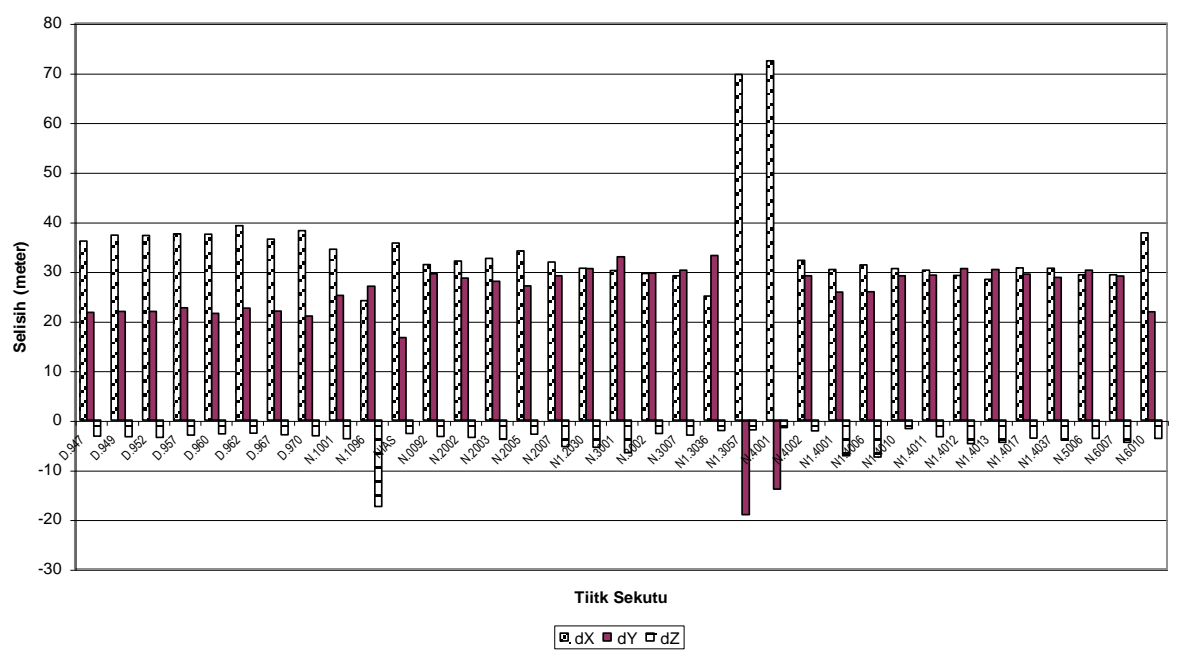

Gambar 2. Selisih Koordinat hasil transformasi menggunakan model Bursa-Wolf dengan nilai koordinat titik sekutu dalam sistem DGN95

Gambar 3 menunjukkan bahwa hitungan model 7 parameter dengan data pada wilayah 1 (18 titik) memberikan hasil penyimpangan rata-rata $\Delta \mathrm{X} \approx 1.495 \mathrm{~m}, \Delta \mathrm{Y} \approx 24.339 \mathrm{~m}$ dan $\Delta \mathrm{Z} \approx 3.852 \mathrm{~m}$

Sedangkan pada Gambar 4 terlihat bahwa hitungan model 7 parameter dengan data pada wilayah 2 (17 titik) memberikan hasil penyimpangan rata-rata $\Delta \mathrm{X} \approx 103.340 \mathrm{~m}, \Delta \mathrm{Y}$ $\approx 27.323 \mathrm{~m}$ dan $\Delta \mathrm{Z} \approx 4.642 \mathrm{~m}$.

Selisih koordinat Hasil Transformasi \& Titik Sekutu -DGN95 (Wilayah 1)

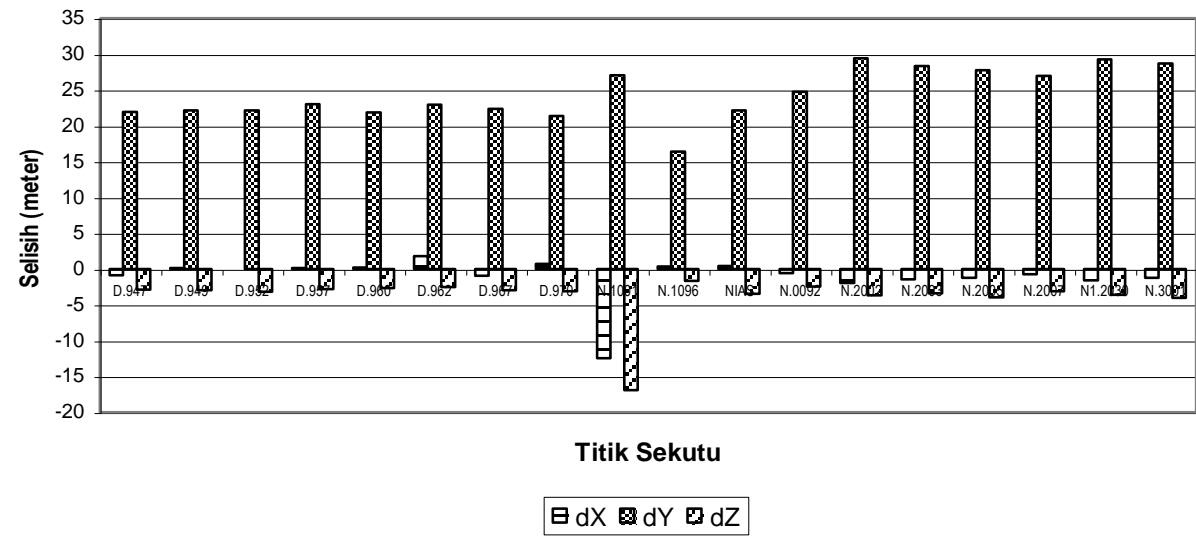

Gambar 3. Selisih Koordinat hasil transformasi menggunakan model Bursa-Wolf dengan nilai koordinat titik sekutu dalam sistem DGN95 Wilayah 1 


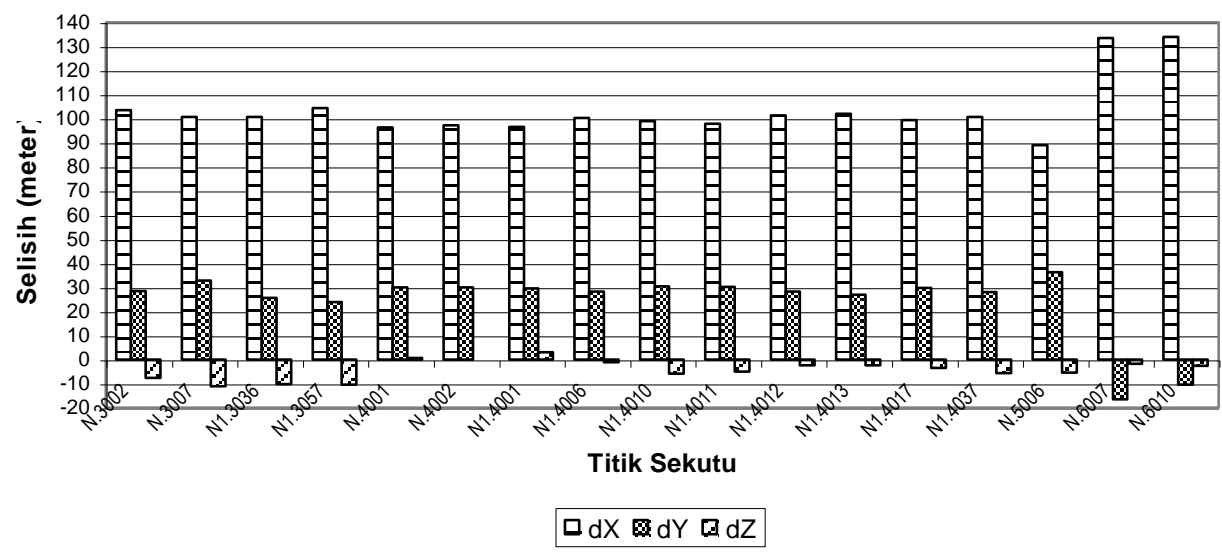

Gambar 4. Selisih Koordinat hasil transformasi menggunakan model Bursa-Wolf dengan nilai koordinat titik sekutu dalam sistem DGN95 Wilayah 2

Hasil transformasi menggunakan model 10 parameter ditunjukkan pada Gambar 5. Dari hasil tersebut terlihat variasi penyimpangan yang tidak teratur. Hal ini disebabkan karena skala tiap sumbu berbeda. Nilai rata-rata penyimpangan $\Delta \mathrm{X} \approx 12.093 \mathrm{~m}, \Delta \mathrm{Y} \approx$ $5.090 \mathrm{~m}$ dan $\Delta Z \approx 1.127 \mathrm{~m}$; Pada Gambar 6 terlihat bahwa model 10 parameter pada wilayah 1 memberikan penyimpangan $\Delta \mathrm{X} \approx 1.422 \mathrm{~m}, \Delta \mathrm{Y} \approx 1.180 \mathrm{~m}$ dan $\Delta \mathrm{Z} \approx 1.512 \mathrm{~m}$; sedangkan pada Gambar 7 terlihat bahwa model 10 parameter pada wilayah 2 memberikan penyimpangan $\Delta \mathrm{X} \approx 21.588 \mathrm{~m}, \Delta \mathrm{Y} \approx 6.595 \mathrm{~m}$ dan $\Delta \mathrm{Z} \approx 0.606 \mathrm{~m}$.

Dari hasil semua model transformasi, dapat dilihat terdapat perbedaan yang besar antara model 7 parameter dan model 10 parameter; Dari setiap model transformasi, daerah timur (wilayah 2), memberikan hasil penyimpangan yang besar dibandingkan dengan daerah barat (wilayah 1). Hal ini menunjukkan tidak homogennya ketelitian jaring kontrol horisontal dalam sistem yang lama (ID74) yang pengukurannya memanfaatkan satelit doppler/transit, pernyataan ini juga diungkapkan dalam Subarja (1995).

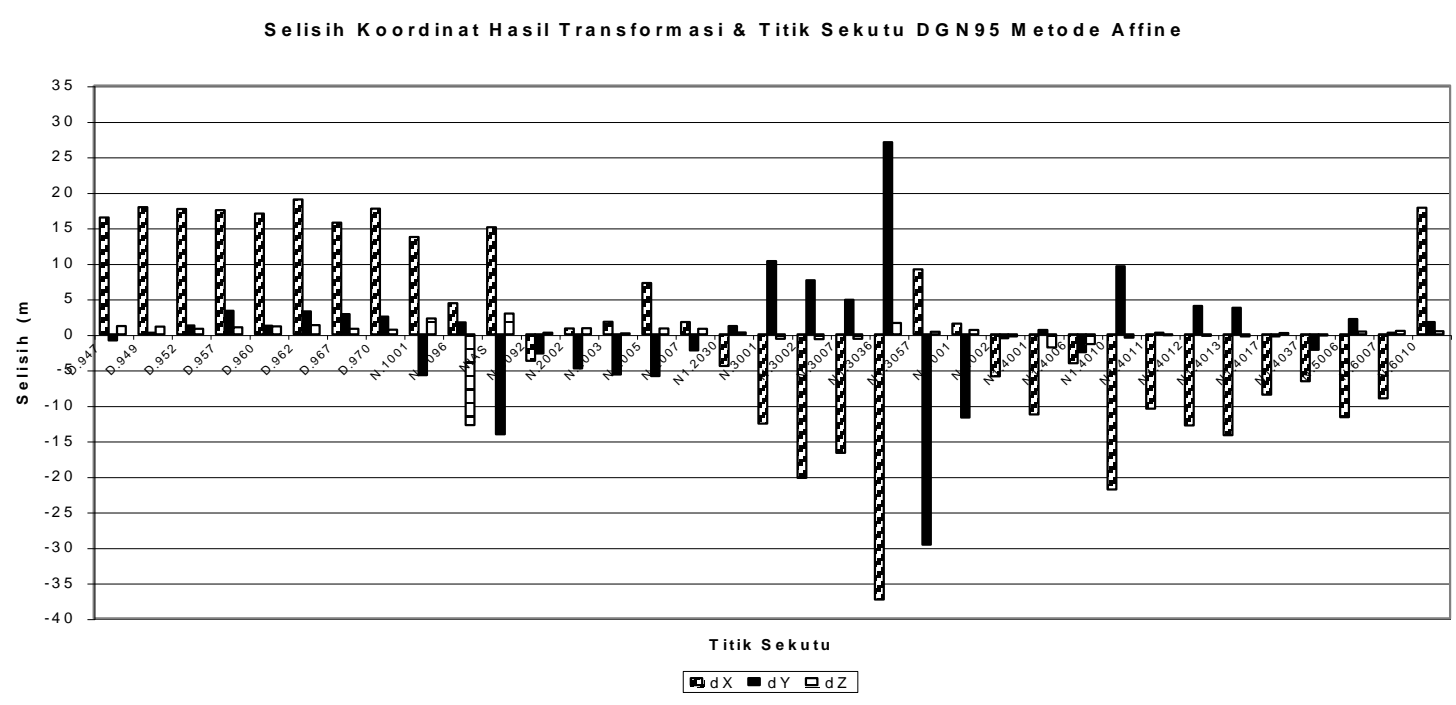

Gambar 5. Selisih Koordinat hasil transformasi menggunakan model 10 Parameter dengan nilai koordinat titik sekutu dalam sistem DGN95 


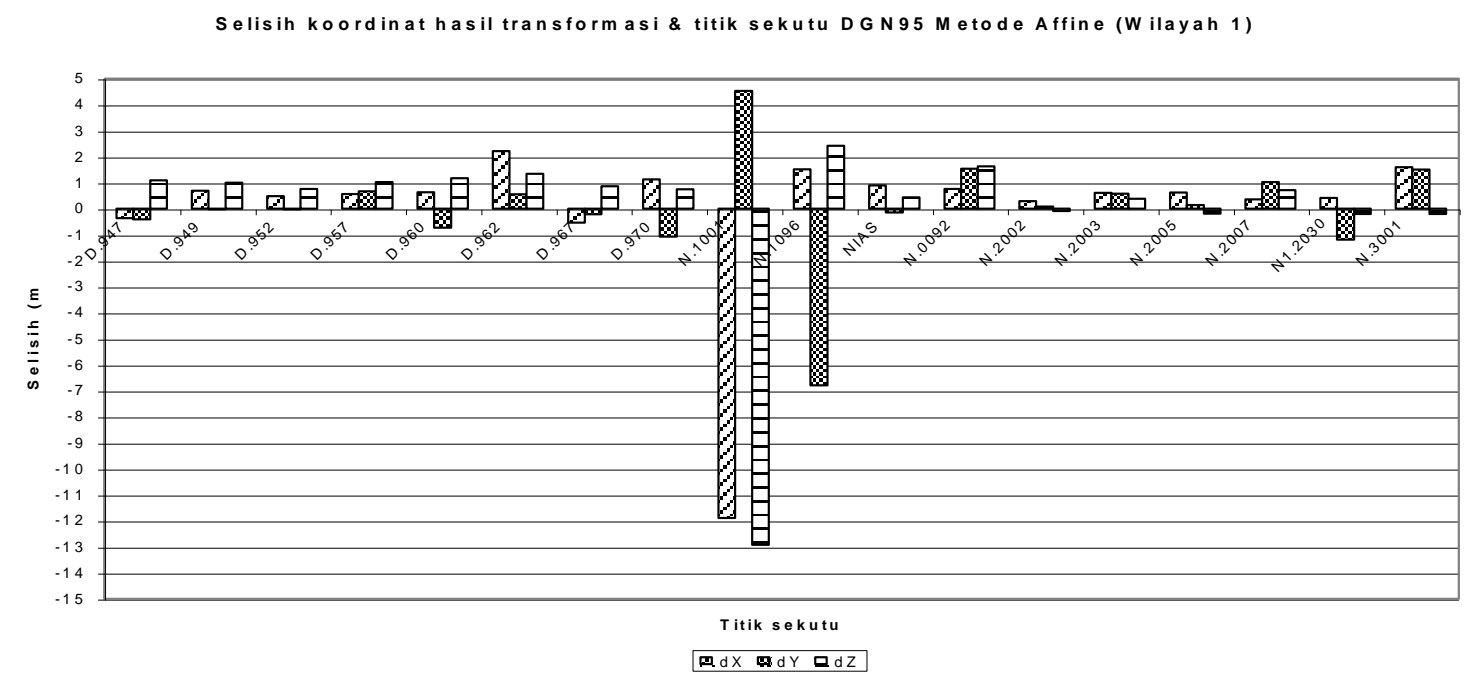

Gambar 6. Selisih Koordinat hasil transformasi menggunakan model 10 Parameter dengan nilai koordinat titik sekutu dalam sistem DGN95 (wilayah 1)

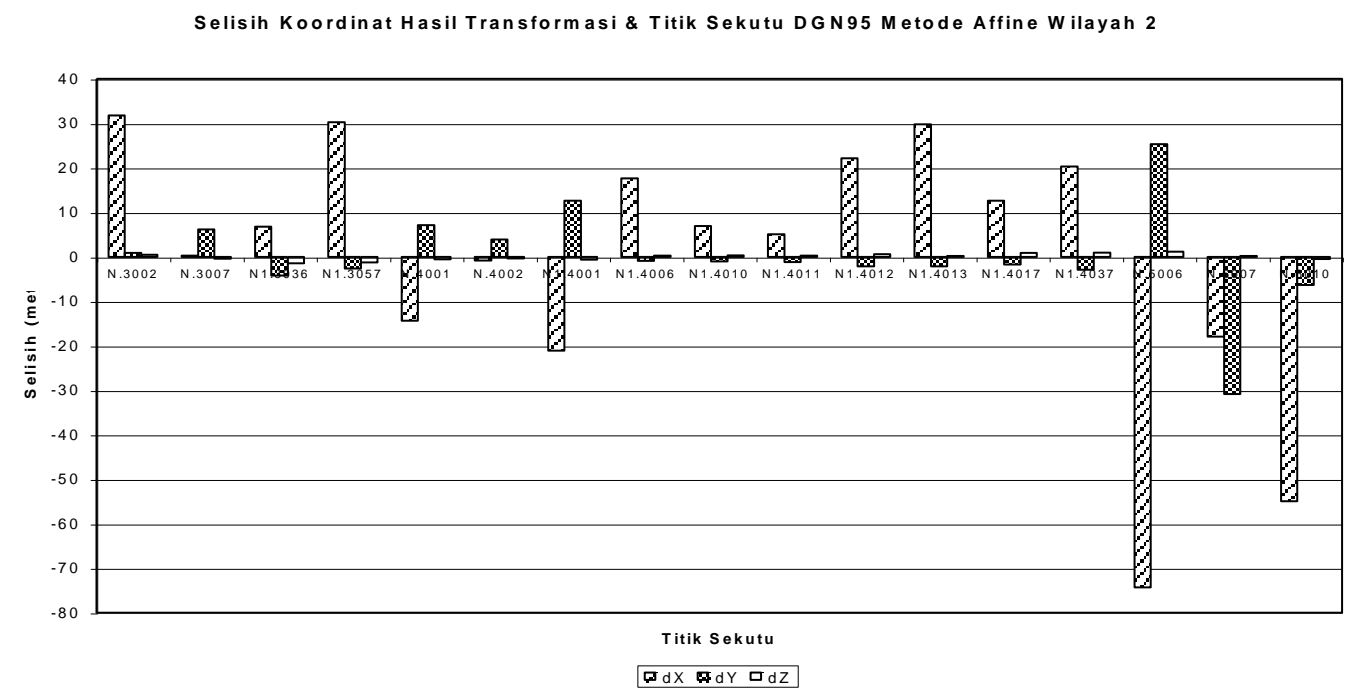

Gambar 7. Selisih Koordinat hasil transformasi menggunakan model 10 parameter dengan nilai koordinat titik sekutu dalam sistem DGN95 ( wilayah 2 )

\section{KESIMPULAN \& SARAN}

Dari analisis hasil hitungan dapat dilihat bahwa penggunaan model transformasi 10 parameter dapat memberikan hasil yang lebih baik dari model Bursa Wolf.

Meskipun begitu perlu dikaji lebih lanjut mengenai kinerja model transformasi 10 parameter dengan distribusi titik sekutu yang baik dan jumlah titik sekutu yang lebih banyak. Selain itu perlu juga dilakukan pembobotan terhadap data ukuran dari sistem ID74 dan DGN95.

Terdapat model transformasi datum menggunakan persamaan multi regresi yaitu Multiple Regression Equation. Penggunaan model ini perlu dikembangkan sebagai pembanding dari model- model yang telah ada. 


\section{DAFTAR ACUAN}

Applebaum, L.T. (1982 ) Geodetic Datum Transformation by Multiple Regression Equation. Proceedings of The Third Geodetic Symposium on Satellite Doppler Positioning, Las Cruces, New Mexico, pp. 207-223

Bomford, G. ( 1980 ) Geodesy ( $4^{\text {th }}$ ed ). Clarendon Press, Oxford.

Bosser, J. D. ( 2002a ) Coordinates and Coordinates System. Bosser, J.D. Ed. Manual of Geospasial Science and Technology, Taylor \& Francis, London. Pp 8-15.

Bosser, J. D. ( 2002b) Datum and Geodetic System. Bosser, J.D. Ed. Manual of Geospasial Science and Technology, Taylor \& Francis, London. Pp 16-26.

Draper, N.R. \& H. Smith ( 1981 ) Applied Regression Analysis - $2^{\text {nd }}$ Edition. John Wiley \& Sons. New York.

Efroymson, M.A ( 1967 ) Multiple Regression Analysis, Ralston, A. Ed. Mathematical Methods for Digital Computers, John Wiley \& Sons, Inc, New York

Habib, A. ( 2002 ) Coordinate Transformations. Bosser, J.D. Ed. Manual of Geospasial Science and Technology, Taylor \& Francis, London. Pp 27-49.

Harvey, B.R. ( 1993 ) Practical Least Squares and Statistics for Surveyors. Monograph 13. School of Surveying-University of New South Wales, Kensington, Australia.

Heiskanen, W.A and Moritz, H. ( 1967 ) Physical Geodesy. W.H. Freeman and Co., San Francisco, CA.

Moffitt, F. and Mikhail, E. ( 1980 ) Photogrammetry ( $3^{\text {rd }}$ ed ). Harper \& Row, New York.

NIMA (1997 ) Department of Defense World Geodetic system 1984, its Definition and Relationships with Local Geodetic System (3rd ed). National Imagery and Mapping Agency TR.8350.2, Bethesda MD

Okeke, F.I ( 1998 ) The Curviliner Datum Transformation Model. Dissertationen Universit ${ }^{\mathrm{TM}} \mathrm{S}$ Stuttgart, M) nchen, German.

Subarya, C \& R.W. Matindas ( 1995 ) Datum Indonesia 1995 (DI-95) yang Geosentrik. Pusat Pemetaan. Bakosurtanal, Indonesia.

Torge, W. ( 1980 ) Geodesy. Walter de Gruyter, New York.

Villanueva, K. J. ( 2001 ) Peran Bakosurtanal dalam Pembangunan Nasional Kepesisiran dan Kelautan Indonesia. Makalah disajikan pada Seminar Nasional Kelautan Ikatan Mahasiswa Geodesi ITB, Bandung. 7 April.

Veis, G. ( 1960 ) Geodetic uses of artificial satellites, Smithsonian Contributions of Astrophysics, vol.3, No. 9, Smithsonian Institute, Washington. D.C.

Wolfrum, O. ( 1992 ) Merging Terrestrial and Satellite Networks by A Ten-Parameter Transformation Model, Manuscripta Geodetica (17) pp.210-214 